\title{
A PROBLEMÁTICA DA HISTÓRIA NO DEBATE "MODERNIDADE versus PÓS- MODERNIDADE": os impactos sobre as noções de fragmentação e globalização
}

SIMONE WOLFF

Docente responsável pela disciplina Informática e Sociedade do curso de Processamente de Dados do Centro de Estudos Superiores de Londrina - CESULON.

Este artigo parte da premissa de que os povos e suas culturas estão sendo incorporados num processo civilizatório totalitário e unificador o qual engendra situações extremamente conflitantes e antagônicas. Esse estado de coisas, já a algum tempo, está suscitando importantes debates teóricos os quais emergem de duas raízes epistemológicas distintas: aquela que entende o momento atual como integrante de um dado processo histórico, representado uma continuidade de algo que foi semeado nos albores da modernidade; e uma outra que o entende como uma desconexão radical com a ordem moderna, sendo impossível qualquer explicação processual sobre o mesmo visto que esse representa antes uma descontinuidade do que uma continuidade com tal status quo. Nesse ensaio pretendemos discutir algumas implicações que esse debate levanta.

Palavras-Chave: Modernidade, Pós-Modernidade, História, Globalização, Fragmentação, Materialismo-Histórico.

\section{INTRODUÇÃO}

$\mathrm{D}$ as inúmeras polêmicas teóricas levantadas no interior das Ciências Sociais em torno da questão da globalização, o debate "Modernidade X Pósmodernidade" é, sem dúvida, um dos mais proeminentes. E, dentre as inúmeras discussões que esse debate suscita, o questionamento da validade do entendimento de um "sentido histórico" como um princípio teórico-metodológico orientador da compreensão do real, constitui um dos - senão o principal - eixo central de críticas de ambos os lados. Num mundo onde as fronteiras estão cada vez mais apagadas e diluídas, onde o regional está sendo mais e mais envolvido e engolido pelo universal e, por conseguinte, as culturas cada vez mais difusas e homogeneizadas, o paradoxo da fragmentação e do (suposto) caos que lhe perpassa é um problema complexo e controverso, ponto chave das contendas entre modernos e pós-modernos.

Grosso modo, enquanto os últimos assinalam a falta de um nexo explicativo para os novos fenômenos em curso afirmando que, perante a imprevisibilidade dos mesmos, não faz mais sentido falar em "sentido histórico" declarando, assim, o fim das metanarrativas; os primeiros apregoam tais acontecimentos como o acirramento de algo inerente à história da modernidade, fruto - entre outras coisas - do constante movimento de superação do espaço por meio do tempo, próprio do processo de produção do capitalismo e que Marx já vislumbrava a mais de um século atrás, reafirmando, portanto, a pertinência de uma interpretação macro para a compreensão do momento atual.

$\mathrm{O}$ presente ensaio pretende expor e demonstrar esse último ponto de vista como o mais apropriado para captar e apreender as transformações que estão ocorrendo hoje no mundo. Dada as limitações que um estudo de caráter ensaístico coloca e levando em conta que a maioria das discussões se concentram em torno das categorias espaço e tempo - como não poderia deixar de ser quando se trata de História -, optei por analisar a problemática proposta a partir do conceito de "compressão do espaço-tempo" desenvolvido por David Harvey. Apesar desse autor de uma certa maneira aceitar a "condição pósmoderna" vigente, a entende, antes de mais nada, como uma "condição histórica" cujas raízes encontram-se na própria modernidade e diz 
respeito, sobretudo, a “(...) experiência do espaço e do tempo como vínculo mediador singularmente importante entre o dinamismo do desenvolvimento histórico-geográfico do capitalismo e complexos processos de produção cultural e transformação ideológica". (HARVEY, 1992 : 09).

Desse modo, com o intuito de melhor elucidar essa questão, iniciarei esse estudo expondo, rapidamente, o olhar teórico-metodológico pósmoderno sobre a história. Tal opção foi feita por entender que estabelecendo, ainda que de forma concisa, o contraponto da problemática apresentada, a análise procederá de forma mais fundamentada. Considerando as várias divergências e nuances conceituais existentes entre os próprios pósmodernos a esse respeito, me respaldarei em Linda Hutcheon posto que, a meu ver, essa autora consegue trabalhar o assunto genérica $e$ sistemáticamente sem, contudo, perder o rigor conceitual, tanto mais por ela mesma considerar-se uma pós-moderna.

É importante, ainda, ressaltar que de modo algum esgotarei todas as polêmicas explícitas e/ou implícitas nesse debate. Como foi colocado acima, o caráter desse estudo restringe maiores aprofundamentos. A intenção é refletir um pouco mais atenta e elaboradamente sobre um problema teórico extremamente preponderante no que concerne à questão da globalização e seus impactos sócio-culturais.

\section{APRESENTANDO O CONTRAPONTO}

Segundo Linda Hutcheon, boa parte do pensamento moderno caracteriza-se pela busca na e pela História de um respaldo fornecedor de subsídios para compreender o cenário de intensa mutação e incertezas desse período. Para a autora, esse respaldo tem muito mais a ver com um certo compromisso ético com os ideais emancipatórios iluministas do que com a complexa e nova realidade que se configura. Na ânsia de encontrar respostas e caminhos para as angústias dos homens modernos, os pensadores modernos, em geral, olhavame olham o passado de forma a reeencontrá-lo no presente; sempre procurando possíveis repetições, generalizações de fatos que pudessem vir a confirmar e corroborar com seus propósitos universalistas, fornecendo, assim, bases mais firmes para o entendimento do turbilhão do mundo moderno (HUTCHEON, 1988 : 121).

Para essa autora, é exatamente esse o ponto crucial que diferencia o tratamento moderno da história com o pós-moderno:

“O que a escrita pós-moderna da
história e da literatura nos ensinou
é que a ficção e a história são
discursos, que ambos constituem
sistemas de significação pelos quais
damos sentido ao passado
('aplicações da imaginação
modeladora e organizadora'). Em
outras palavras, o sentido e aforma
não estão nos acontecimentos, mas
nos sistemas que transformam esses
'acontecimentos' passados em
'fatos' históricos presentes. Isso não
é um 'desone sto refúgio para
escapar à verdade', mas um
reconhecimento da função de
produção de sentido dos construtos
humanos. (...) o historicismo pós-
moderno está voluntariamente livre
da nostalgia”. (idem, p. 122)

Ou seja, o pensamento pós-moderno trabalha com a história considerando-a como algo carregado de valores e representações simbólicas não só da época - o que dificulta sobremaneira determinar os reais sentidos das ações e relações sociais do contexto estudado, posto que impossível apreender todas as nuanças simbólicas nele embutido -, mas, e principalmente, do momento presente e dos atores envolvidos nessa conjuntura. A história entendida dessa forma adquire uma conotação antes subjetiva do que objetiva, pois dependente de como os atores (por mais coletivos que sejam) e os relatores desse processo experenciam os acontecimentos passados e presentes. A história pós-moderna é, antes de mais nada, interpretativa, ou seja, visa sempre entender os motivos pelos quais certos fatos históricos foram escolhidos como relevantes em detrimento de outros.

Remeter-se ao indivíduo e enfatizar os aspectos subjetivos e mesmo psicológicos que lhes perpassam na hora da escrita histórica é o único meio de fugir de determinismos históricos os quais, via de regra, acabam por sacralizar a história relegando a um segundo plano os sujeitos que a integram. Há, assim, que se abandonar as metanarrativas históricas com suas leis gerais e universalizantes apontando uma 
direção histórico-social pré-determinada e atentar para o contexto particular dessa formação histórica, isto é, compreender as representações e valores que agiram nos sujeitos influindo em suas ações e consequentes reações perante o meio vivido, visto que é a partir daí que dadas realidades se constituem ou não.

“São as aplicações explicativas e
narrativas que a historiografia dá
aos acontecimentos passados que
constroem aquilo que consideramos
como fatos históricos. Esse é o
contexto em que a compreensão
histórica pós-moderna se situa: fora
das associações de progresso ou
desenvolvimento iluministas, do
processo idealista/hegeliano da
história do mundo, ou de noções
marxistas essencializadas a respeito
da história. (...) O passado realmente
existiu.A questão é: comopodemos
conhecer esse passado hoje -e o que
podemos conhecer a seu respeito?
(...) Qual a natureza ontológica dos
documentos históricos? Será que
eles substituem o passado? o que
se dizer - em termos ideológicos -
quando se fala em nossa
compreensão 'natural' sobre a
explicação histórica?” (ibidem p.
l26-127 - negritos próprios).

Percebe-se, assim, que o pensamento pósmoderno sobre a história faz questão de ressaltar o caráter ideológico dos escritos históricos. É sob esse ponto de partida, inclusive, que reside uma das principais críticas dos pós-modernos em relação à historiografia moderna a qual vêem como uma espécie de camisa-de-força dos fatos históricos, sempre procurando enquadrá-los em seus pressupostos totalizadores e teleológicos.

“(...) o teórico e o crítico estão
inevitavelmente envolvidos com as
ideologias e as instituições ... existe
uma deliberada contaminação do
histórico pelos elementos discursivos
didáticos e situacionais, contestando
assim pressupostos implícitos das
afirmações históricas: objetividade,
neutralidade, impessoalidade e
transparência
representação." (Idem, p. 125). da

Nota-se, então, que o argumento de que a ideologia é algo inerente às narrativas históricas modernas é, via de regra, a base principal de argumentação de grande parte dos pensadores pósmodernos para privilegiar o discurso em detrimento da historiografia tradicional a qual, acreditam, ao impôr "(...) um sentido ao passado por meio de uma pressuposição de um final (e/ou uma origem)" não difere muito da ficção (ibidem, p. 132). A ênfase ao discurso pemite, assim, que se assuma o caráter provisório, plural e multifacetado dos relatos históricos, mais condizente com a multiplicidade sócio-cultural vigente, contrariamente às metanarrativas que acabam por sobrepujar as diversidades através de sua epistemologia unificadora. Sob a ótica pós-moderna:

"O estudo das forças anônimas de
dissipação substitui o estudo dos
acontecimentos e das realizações
'assinalados', cuja coerência é
dada pela narrativa retrospectiva;
as contradições desalojam as
totalidades; as descontinuidades, as
lacunas e as rupturas são
privilegiadas em oposição à
continuidade, ao desenvolvimento,
à evolução; o particular e o local
assumem o valor antes mantido
pelo universal e pelo transcedental.
(...) Para a história, a teoria e a arte
pós-modernas, isso significou uma
nova consideração sobre o
contexto, a textualidade, o poder de
totalização o os modelos de história
contínua" (Ibidem, p. 132 - negritos
próprios)

O problema é saber como os indivíduos e suas subjetividades, múltiplas e variáveis, subsidiarão a compreensão da existência (empíricamente inegável) de relações sociais mais amplas e de como as mesmas se constituíram em uma totalidade social abrangente (cuja existência também não se pode negar), tanto que é capaz de retroagir ideológicamente, como os próprios pós-modernos (contraditóriamente) afirmam e confirmam em sua crítica à história moderna, sobre os discursos e narrativas historiográficas. A crença dos pósmodernos numa análise hermenêutica da história, que priorize e enfatize os aspectos subjetivos de quem as conta como única forma de desmitificar a história, paradoxalmente acabam por salientar a preponderância da ideologia, categoria 
indubitavelmente ampla e genérica, por mais que haja nuanças conceituais de interpretações em seu entendimento. Ao tentarem resolver o "despotismo e autoritarismo" da história tal como é concebida nos moldes, segundo eles, simplificadores do paradigma moderno, istoé, pela tendência, em suas explicações, de introduzir leis gerais e imutáveis na sociabilidade humana, os pós-modernos recorrem a um recurso eminentemente genérico. Baseiam, assim, seus propósitos e compromisso com o complexo no reconhecimento de uma não neutralidade científica como se isso resolvesse o problema teórico-metodológico de seus pressupostos. Como e porquê essa ideologia se constitui, parece não fazer parte das preocupações e princípios explicativos dos pós-modernos.

É claro que não se trata de menosprezar a importância da ação do sujeito, mas antes de sabêla orientada em sua pluralidade. E essa orientação, como as próprios teóricos pós-modernos admitem, é imprimida pela ação da ideologia nos atores sociais. Ora, admitir essa influência sem se preocupar em saber sobre que bases ela é construída, sem procurar desvendar o por quê que esses valores se efetivaram, é ficar na aparência e não ir à essência, os fatos e acontecimentos históricos acabam se tornando meras descrições de como certos interesses individuais agruparam-se num dado momento e formaram uma dada realidade e não outra. Analisa-se o efeito e não a causa, é quase como se se decretasse o fim das ciências humanas.

Ademais, no que se refere a questão da complexidade do real - sobretudo do momento atual - o simples fato de reconhecê-la e aceitá-la epistemológicamente parece um argumento um tanto fraco, assim como justificar a prevalência do discurso e das partes como recurso metodológico importante (e único possível) diante do complexo e do inusitado carece de maiores fundamentos. Com efeito, o reconhecimento do complexo não é privilégio apenas do pensamento pós-moderno. As complexidades que se apresentam e sempre estiveram presentes no mundo moderno não descartam necessariamente o holismo metodológico, mas antes desafiam-no a encontrar e recriar conceitos, ressignificar categorias que sejam mais adequadas a essa nova realidade a qual, apesar de complexa, nem por isso é menos históricamente dada. E é justamente isso o que David Harvey faz mediante seu conceito de "compressão do espaço-tempo" que veremos a seguir.

\section{A GLOBALIZAÇÃO ENQUANTO A EXPRESSÃO DE UM FENÔMENO HISTÓRICO}

De acordo com David Harvey, essa ruptura epistemológica em relação à história, que se insere no debate "Modernidade X Pós-modernidade", tem a ver com o movimento de constante superação do espaço por meio do tempo, próprio da dialética das crises de circulação e consumo característica da produção capitalista e que tende a exacerbar-se de tempos em tempos ocasionando "(...) processos que revolucionam as qualidades objetivas do espaço e do tempo a ponto de nos forçarem a alterar, às vezes radicalmente, o modo como representamos o mundo para nós mesmos" (HARVEY, 1992 : 219). É o que ele denomina de "compressão do tempo-espaço", ou seja, a expansão e acirramento de um processo econômico-civilizatório - qual seja, o capitalismo - que, para manter-se e perpetuar-se, necessita de estar sempre em busca de novos mercados. As decorrentes tecnologias inventadas para agilizar tal processo proporcionam, em certos momentos, uma tal dissolução, integração e desintegração de fronteiras geográficas e históricas e um consequente contato entre culturas, que provoca uma sensação de que o futuro já é, que chegamos ao "fim da estrada" e não se tem mais por onde seguir. É uma fase de intensa mutação da noção espácio-temporal permeadas por verdadeiros choques culturais que estilhaçam nossa realidade ao mesmo tempo que a universaliza.

Para Harvey, ao mesmo tempo que essa dinâmica gera uma padronização de valores, paradoxalmente salienta as diversidades e desigualdades sociais, trazendo conflitos e tensões, consequentemente, inseguranças e confusões. A insegurança surgida dessa intensa fragmentação, que a lógica da acumulação coloca, impacta no imaginário das pessoas fazendo-as tomarem a sensação pela realidade. Como não pode deixar de ser, esse estado de coisas repercurte nas artes, filosofia e ciências humanas derivando muitas reflexões que se apegam nesse momento "sui generis" como se fosse algo completamente inédito e, portanto, que deve ser entendido e interpretado 
também de maneira inédita. Normalmente essas análises passam a privilegiar as histórias, símbolos e mitos locais na ânsia de encontrar as identidades perdidas nessa miscelânea cultural proporcionada pela globalização do capital.

Para Harvey, então, trata-se de conectar as mudanças sócio-culturais em curso às mudanças político-econômicas vigentes, isto é, apresentando essas duas esferas da estrutura social como interrelacionadas e inter-dependentes, cada uma agindo e retroagindo sobre a outra. Aceitando a tese de Berman de que um dos princípios definidores da modernidade é uma peculiaridade na forma de vivenciar o tempo e o espaço decorrente da eterno movimento contraditório de construção/destruição característico dessa época, Harvey contudo, vai além dessa afirmação buscando conceituar mais rigorosamente tais categorias de modo a melhor apreender a influência que essa experiência confere ao atual debate "Modernidade X Pós-modernidade" (entendendo sempre essa última como estreitamente ligada ao processo de "(...) transição do fordismo para modalidades mais flexíveis de acumulação do capital através das mediações espaciais e temporais") (idem, p. 187).

Seguindo, pois, uma perspectiva materialista histórica procurando, porém, fugir de ortodoxismos na medida em que a concebe como algo dinâmico e, enquanto tal, em constante readequação com as especificidades do momento, Harvey busca as raízes da mudança cultural e teórica em voga na flexibilização da economia, a qual “(...) teve muito que ver com a superação da rigidez do fordismo e com a aceleração do tempo de giro como solução para os graves problemas do fordismokeynesianismo" (ibidem, p. 257), requerendo, assim, formas mais sutis e criativas de manipulação dos consumidores e agentes produtivos como garantia de manutenção do status quo. Entendendo que a aceleração no tempo de giro da produção impacta do mesmo modo nas demais esferas desse processo, isto é, a troca e o consumo, Harvey destaca as transformações na "arena do consumo" como o principal fator de influência "(...) nas maneiras pósmodernas de pensar, de sentir e de agir" (ibidem, p. 258).

Harvey aponta a tendência cada vez mais premente do mercado global em buscar novas estratégias de aquecimento e incrementação do consumo através da criação de novas mercadorias e necessidades também mais flexíveis, ou seja, mais independentes dos bens materiais - que encontraram seu apogeu sob o fordismo - os quais, em função de sua durabilidade, impõem limites instransponíveis para a atual propensão do regime de acumulação e sua exigência na aceleração do tempo de giro. Assim, a saída encontrada pelos capitalistas para acelerar o ritmo do consumo foi investir e jogar no mercado produtos que tivessem tempo de vida curto e fossem de fácil adaptação, mais de acordo com o período de intensa expansão, inovação e transformação que o mercado vem sofrendo. Para tanto, a adoção dos serviços em detrimento dos bens materiais enquanto mercadoria de consumo, assim como o emprego de modismos que viessem a moldar um novo estilo de vida e, portanto, de consumo passou a ser parte fundamental das novas diretrizes políticoeconômicas em tempos de mercado global e acumulação flexível. Nunca, na história do capitalismo, sua característica de "criação destrutiva" e "destruição criativa" (idem, p. 26) esteve tão veemente. Nunca as obsolências foram tão necessárias e as novidades tão ágeis e rotativas.

Desse modo, Harvey coloca que essa exacerbada ênfase na efemeridade e volatilidade das mercadorias acaba por acentuar a "(...) sensação de que "tudo que é sólido desmancha no ar"' (idem, p. 258), própria do modo de ser do capitalismo, na medida em que - ao sobressair-se a instantaneidade/ efemeridade e a descartabilidade/volatilidade - os valores, costumes, instituições, representações sociais etc., também tornam-se voláteis/descartáveis e efêmeros/instantâneos o que, em última instância, significa que os mesmos também passam a ter um tempo de vida curto e flexível, sofrendo drásticas e rápidas mutações. Consequentemente, surge uma nova cultura como resultado e suporte da atual "condição pós-moderna", uma cultura que - via de regra - priviligia a estética, o momento, o fragmento, a quantidade em oposição à cultura de massa, qualitativa e monolítica própria da era fordista.

Como o rei Midas que transforma tudo que toca em ouro, a sociedade burguesa transforma tudo que toca em mercadoria. Assim acontece também com os valores e culturas. Não só novos valores são construídos para respaldar essa sociedade como velhos valores são destruídos e/ ou absorvidos e aproveitados segundo seus interesses. Assim é que nesse novo contexto, a imagem transformou-se em mercadoria preponderante e mais condizente com o novo capitalismo, isto é, eminentemente volátil, flexível, rápida, adaptável e multifuncional. Serve tanto à 
fluidez necessária ao novo mercado como para o estabelecimento de uma marca, de uma identidade que possibilite dados produtos (dependento do grau de criatividade que os mesmos comportam) a conquistar um espaço um pouco mais durodouro num mercado tão veloz e competitivo. Osimulacro, uma variante da imagem enquanto mercadoria, também sobressai-se como elemento relevante nesse processo na medida em que revela-se extremamente eficiente em mascarar as realidades passadas e futuras vendendo uma imagem romantizada sobre as mesmas. Para Harvey o simulacro, ao poetizar os fatos históricos, encobre os conflitos e a exploração de classe anulando, assim, eventuais resistências nesse sentido e contribuindo para a padronização das subjetividades.

Dentro desse contexto, o status individual passa a ter uma conotação ainda mais importante do que sempre teve nessa sociedade. Por conseguinte, a venda de imagens, auto-imagens e simulacros tornam-se um grande negócio, uma verdadeira mega-indústria que "(...) organiza as manias e modas, e, assim fazendo, produz a própria efemeridade que sempre foi fundamental para a experiência da modernidade. Ela se torna um meio social de produção do sentido de horizontes temporais em colapso de que ela mesma, por sua vez, se alimenta tão avidamente." (ibidem, p. 262 negritos próprios).

Esse mutante universo, aparentemente fragmentário e caótico, saturado de imagens e bricolagens, onde o espaço perde cada vez mais o significado em meio à rapidez e exacerbamento do fluxo de informações, provoca a impressão do que Harvey chama de "perda de um sentido do futuro" (p. 263). A volatilidade e efemeridade em voga, aliada às novas tecnologias inventadas para otimizar esse processo - produzindo um cenário high tech , mesclam o presente e o futuro dando a sensação de que não há nada mais que se esperar, de que já aconteceu o que tinha que acontecer. Esse fato é tanto mais agravado quando se constata que as heterogeneidades culturais, cujas raízes sempre estiveram ligadas às localidades territoriais, também são envolvidas e solapadas pela intensa competitividade que a nova forma de acumulação coloca, sendo levadas de roldão nesse turbilhão e acarretando uma homogeneização cultural generalizada e conflituosa. Quando muito as localidades e diferenças culturais sobressaem apenas para ficarem mais atraentes ao capital financeiro também esse imagético e fictício, em conformidade ao novo regime de acumulação - e ao novo processo produtivo, tornando-se, também, mercadorias. (ibidem, p. 266)

Desse modo, cada vez mais as pessoas procuram "descontar o futuro do presente" na tentativa de aplacar a angústia da perda de seus sonhos e projetos. Nesse ponto que a questão da continuidade $\mathrm{X}$ descontinuidade histórica entra no centro das discussões teóricas, filosóficas e culturais. Segundo Harvey:

"Esse é, com efeito, o tipo de
ambiente em que o
desconstrucionismo pode florescer.
Se é impossível falar alguma coisa
da solidez e da permanência em
meio a este mundo efêmero e
fragmentado, por que não entrar no
jogo [da linguagem]? Tudo, da
escriturade romances edofilosofar
à experiência de trabalhar ou
construir um lar, tem de enfrentaro
desafio do tempo de giro em
aceleração e do rápido
cancelamento de valores
tradicionais e históricamente
adquiridos. Nessa circustância, o
contrato temporário inerente atudo
se torna, como observa Lyotard, a
marca da vida pós-moderna.
(ibidem, p. 263)

Contudo, o que os autores pós-modernos parecem não conseguir perceber é que a fragmentação faz parte da natureza do capitalismo e, tal qual qualquer outra mercadoria, é produzida e/ou cooptada como um artifício de auxílio à manutenção de seus interesses. ${ }^{2} \mathrm{O}$ caos, a fragmentação, a desintegração são elementos não só constituintes, mas extremamente necessários no universo da modernidade visto que viabiliza o surgimento de novas e renovadas oportunidades de reconstrução, manipulação e perpetuação do sistema o qual se alimenta desse movimento de construção-destrução que lhe é próprio. Segundo Harvey esse fato constitui o "paradoxo central" inerente ao capitalismo:

"quanto menos importantes as barreiras espaciais, tanto maior a sensibilidade do capital às variações do lugar dentro do espaço ${ }^{3}$ e tanto maior o incentivo para que os lugares se diferenciem de maneiras 
atrativas ao capital. O resultado tem sido a produção da fragmentação da insegurança e do desenvolvimento desigual efêmero no interior de uma economia de fluxos de capital de espaço global altamente unificado. A tensão histórica dentro do capitalismo entre centralização $e$ descentralização tem sido trabalhada agora de novas maneiras." (ibidem, p. 267)

Dada opacidade das relações sociais capitalistas, esse processo é escamoteado e fetichizado “(...) de tal modo que oculta de maneira quase perfeita quaisquer vestígios de origem, dos processos de trabalhos que o produziram ou das relações sociais implicadas em sua produção." (lbidem, p. 271). Em função disso, o impacto desses fenômenos na proposições teórico-metodológicas de cunho pós-moderno tem sido uma crescente desconsideração e descrédito nas epistemologias fundadas em conceitos explicativos macros e um privilegiamento do momento e das particularidades locais por entender que a apreensão de uma totalidade é impossível e inatingível posto que o real se encontra completa e definitivamente estilhaçado.

Ainda de acordo com Harvey essa perspectiva teórica, ao desarticular tempo e espaço passa a tomar a aparência pela essência, contribuindo ainda mais para a consolidação e acirramento da fragmentação. Para ele, a consequência dissoé a sobressalência da estética em detrimento da ética gerando uma apatia teórica que pode ser deveras perigosa políticamente. À medida em que sobrepuja a reflexão sobre os problemas globais substituindo-os pelos nacionais, esse tipo de pensamento corrobora e justifica o surgimento ou ressurgimento de nacionalismos extremados e reacionários que inaugura novos tipos de radicalismos e racismos e, por conseguinte, novos conflitos e antagonismos. Ou seja, a emergência do postulado pós-moderno, assim como as demais instâncias, instituições, relações sociais etc. surgidas e/ou ressignificadas no atual contexto pós-moderno é antes uma resposta a uma condição de "compressão do tempo-espaço" e, portanto, integrante de um processo que é histórico e está estreitamente vinculado às mutações políticoeconômicas pelas quais estamos passando nos últimos tempos:

"A intensidade da compressão do tempo-espaço no capitalismo ocidental a partir dos anos 60, com todos os seus elementos congruentes de efemeridade e fragmentação excessivas no domínio político e privado, bem como social, parece de fato indicar um contexto experencial que confere à condição da pósmodernidade o caráter de algo um tanto especial. Contudo, situando essa condição em seu contexto histórico, como parte de uma história de ondas sucessivas de compressão do tempo-espaço geradas pelas pressões de acumulação do capital - com seus perpétuos esforços de aniquilação do espaço por meio do tempo e de redução do tempo de giro -, podemos ao menos levá-la para o âmbito de condição acessível à análise $e$ interpretação materialista histórica." (ibidem, p. 276).

\section{CONSIDERAÇÕES FINAIS}

Desde os seus primórdios o capitalismo se apresenta como uma matriz importante no que diz respeito a alteração de modos de ser. A constante busca de novos mercados, imprescindível para a manutenção de sua lógica, e o consequente intercâmbio de mercadorias que esse movimento coloca nos demonstra que o capitalismo, longe de ser somente um processo econômico, revela-se um processo civilizatório complexo e contraditório responsável por mudanças drásticas de condições de vida. O incessante dinamismo desse movimento - que, apesar de incessante nunca é homogêneo -, tende a exacerbar-se em determinadas épocas denotando momentos particularmente eletrizantes. São momentos históricos importantes e conturbados que colocam um conjunto de desafios e inquietações sociais levando os indivíduos a tratarem desses problemas sem se darem conta de seus dilemas.

Ao que tudo indica estamos vivenciando um desses momentos. Conectar as contradições, rupturas, transformações e ressignificações que estamos experimentando atualmente com esse processo dinâmico próprio do capitalismoé o grande desafio que se coloca. Entender esse momento cuja última expressão é o globalismo - como fruto, 
sobretudo, do imbricamento conflituoso de história geral e histórias particulares, como parte, portanto, de um processo maior e antigo, é o único meio de não nos perdermos num emaranhado de acontecimentos à primeira vista confusos e sem nexo e cometer equívocos teóricos políticamente perigosos em épocas de renovação de valores.

Quando voltamos nossa atenção para as inúmeras histórias presentes e abarcadas nesse processo, deparamo-nos com uma multiplicidade de fatos que repercurtiram e continuam repercurtindo - ainda que de outras formas - em nosso horizonte, num constante recriar. Fatos esses socialmente construídos que contribuíram e contribuem para a formação de uma conjuntura mais ampla.

Dentro desse contexto, é impossível pensarmos em estagnação, em um universo acabado e nivelado ou múltiplo e particularizado. Os homens nunca param de fazer história, isto é, nunca param de intervir no mundo, pois senão simplesmente desapareceriam. Nesse sentido, história e vida são uma única e mesma coisa já que a história nunca se dá separadamente da produção e reprodução humana, ou seja, da relação dos homens entre e si e com a natureza, substrato de sua história. Portanto, enquanto houver vida há história e, enquanto houver história há possibilidades de mudanças. Vida, tempo, espaço e história formam uma rica e fecunda equação.

Vimos que o tempo e o espaço no capitalismo também são social e históricamente construídos e, enquanto tal, possuem uma especificidade própria. $\mathrm{O}$ antagonismo inerente a esse determinado modo de vida tem a peculiaridade de transformar o tempo, categoria eminentemente abstrata e maleável em seu oposto, isto é, numa coisa que, ao ser somada com o trabalho humano gera uma terceira coisa: o lucro. Lucro esse que, ao ser apropriado por apenas uma pequena parcela da sociedade provoca uma profunda situação de desigualdade. Nesse contexto que o espaço também é construído pois conquistado para perpetuar essa lógica.

Portanto, conceber o tempo e o espaço desvinculado dessa prática social e histórica - posto que específica do capitalismo - e de todas suas implicações subsequentes, quais sejam, alienaçãoe conflito, racionalidade e fetichismo, contradição e transformação, revolução e reação, entre outras coisas, é pensar os mesmos desvinculados de seu próprio fundamento, ou seja, a história. Essa desconexão entre tempo, espaço, produção de vida e história, entendendo-os tão-somente como mera sistematização e otimização da lógica capitalista, atende e vem de encontro com as relações sociais características dessa estrutura social. Relações essas eminentemente dicotômicas e instáveis, pois de dominação e subordinação, de apropriação e expropriação, de manipuladores e manipulados.

Refletir o fenômeno da globalização em curso e as inovações que o mesmo coloca teórica e empíricamente é, portanto, tentar perceber como história e produção articulam-se nesse momento e detectar todas as contradições que essa inter-relação aponta, atentando sempre para a extrema fragilidade desse sistema. Um sistema que ao inovar e expandir a produção - movimento sine qua non para sua reprodução - cria e recria novas formas de relações sociais e, assim sendo, ao mesmo tempo que engloba as mais variadas organizações sociais, origina relações sociais prenhes de especificidades difíceis de controlar; ao mesmo tempo que estende seus tentáculos em todos os territórios possíveis de se tornarem mercado, abala as antigas estruturas produtivas locais que até então se pensava completamente consolidadas, provocando distúrbios e agravando tensões; ao mesmo tempo que introduz e cria novas necessidades de consumo em seus novos e velhos mercados, incita um extrativismo sem precedentes colocando em risco seus meios de produção originários. Logo, refletir sobre o fenômeno da globalização é compreender que as partes e o todo configuram-se como algo que, embora complexo, caminham juntos e articuladamente, cheios de sentido.

O capitalismo movimenta-se em um solo arenoso e movediço, ainda que fértil e produtivo, suas constantes revoluções nada mais são que uma tentativa desesperada de enraizar-se nesse chão. Perceber que cada movimento nesse sentido inaugura uma etapa histórica integrante de um processo fecundo e vazio, construtivo e destrutivo, inovador e reacionário, universal e fragmentário, é perceber a possibilidade de fincarmos as bases para uma outra história.

\section{NOTAS}

1 Nesse sentido que Berman afirma que "(...) a cultura moderna [também faz] parte da moderna indústria. Arte, ciências físicas, teoria social (como a do próprio Marx), tudo isso são modos de produção; a burguesia controla os meios de produção na cultura, como em tudo mais, e quem quer que pretenda criar deve operar em sua órbita de poder. ... [Os intelectuais e artistas como] 
membros do proletariado ... só escreverão livros, pintarão quadros, descobrirão leis físicas ou históricas, salvarão vidas, se alguém munido de capital estiver disposto a remunerá-los. Mas ... ninguém os remunerará sem o correspondente retorno, isto é, sem que o seu trabalho não colabore de algum modo para 'incrementar o capital' " (BERMAN, 1986 : 113-114).

2 Um bom exemplo da maneira como essa fragmentação, em termos culturais, é produzida artificialmente revelando-se como parte integrante do processo civilizatório capitalista, está presente em Marx quando ele discorre sobre a teoria da moderna da colonização salientando sua tentativa de se reproduzir nas Colônias as relações capitalistas de produção como forma de neutralizar a resistência dos produtores diretos que lá havia através da dissociação dos mesmos de seus meios de produção. Isso demonstra a imposição do capitalismo às outras formas de organização social. (MARX, 1984 : 295-302)

3 Harvey estabelece uma diferença dicotômica entre espaço e lugar. Para ele, o espaço seria algo mais amplo e geral que abarcaria as localidades, essas mais ligadas ao ambiente e responsável pela diversidades culturais que o espaço integra. (p. 190-191)

\section{REFERÊNCIAS BIBLIOGRÁFICAS}

BERMAN, Marshall. Tudo que é Sólido Desmancha no Ar - as aventuras da modernidade. São Paulo: Companhia das Letras, 1986.

CHALHUB, Samira (org.). Pós-Modernidade \&. Rio de Janeiro: Imago, 1984.

FEATHERSTONE, Mike. Cultura de Consumo e Pós-Modernismo. São Paulo: Studio Nobel, 1995.

GIDDENS, Anthony. As Consequências da Modernidade. São Paulo: Ed. Unesp, 1991.

HARVEY, David. Condição Pós-Moderna - uma pesquisa sobre as origens da mudança cultural. São Paulo: Loyola, 1992.

HUTCHEON, Linda. Poética do PósModernismo. Rio de Janeiro: Imago, 1991.

IANNI, Octavio. A Crise de Paradigmas na Sociologia. Campinas: IFCH/UNICAMP, 1990.

IANNI, Octavio. Teorias da Globalização. São Paulo: Civilização Brasileira, 1995.

LYOTARD, Jean-François. O Pós-Moderno explicado às crianças. Lisboa: Publicações Dom Quixote, 1993.
MARX, Karl. O Capital. São Paulo: Abril Cultural, 1984. Vol. I, Tomo 2. "A Teoria Moderna da Colonização".

MARX, Karl e ENGELS, Friedrich. Manifesto do Partido Comunista. Petrópolis: Vozes, 1988.

MARX, Karl e ENGELS, Friedrich. Textos Escolhidos. São Paulo: Edições Sociais, 1977. Vol. 3, "Futuros resultados do domínio britânico na Índia". 